\section{Sobre infância e filosofia:} suspensão, profanação e atenção na experiência de formação

Alice Pessanha Souza de Oliveira Graduada en Filosofia

Universidad Estatal de Rio de Janeiro - Brasil

alicepessanha11@hotmail.com

http://orcid.org/o0oo-0002-0634-2277

\section{Juliana Braga Teperino}

Graduada en pedagogía

Universidad Estatal de Rio de Janeiro

- Brasil

jbteperino@hotmail.com

https://orcid.org/0000-0002-9829-2763

\section{Luiz Fernando Sales}

Estudiante de Maestria en Educación Universidad Estatal de Rio de Janeiro - Brasil

lfreissales@gmail.com

https://orcid.org/0000-0002-9703-1422

Artículo de reflexión

Recepción: 15 de enero de 2019 Aprobación: 10 de marzo de 2019 https://doi.org/10.19053/22160159.v10.n23.2019.9724

\section{Resumo}

Esse artigo tem por objetivo pensar a própria experiência enquanto estudantes de graduação e mestrado em formação para o trabalho com a filosofia e a infância. Para isso abordaremos a Experiência de Formação realizada pelo Núcleo de Estudos de Filosofias e Infâncias nos anos de 2017 e 2018. Esse artigo propõe pensar em que medida a experiência de formação não se constitui apenas como um curso de formação em filosofia com crianças, mas um tempo escolar que é capaz de modificar nossa relação com o conhecimento. Assim, propomos fazer uma descrição do curso: como ele ocorre, a divisão dos grupos, a dinâmica e a metodologia. Com isso, trabalharemos o conceito de infância, conceito que foi a proposta do nosso grupo em 2017. Por último abordaremos os pedagogos belgas Masschelein e Simons, para pensarmos três aspectos do escolar: atenção, profanação e suspensão. Pensaremos em que sentido esses aspectos estariam presentes na experiência de formação e como eles influenciaram a transformação da nossa relação com 0 conhecimento.

Palavras-chave: filosofia com crianças, infância, atenção, profanação, suspensão 


\title{
Sobre infancia y filosofía: suspensión, profanación y atención en la experiencia de formación
}

\section{Resumen}

Este artículo tiene como objetivo pensar en la experiencia propia, en calidad de estudiantes de pregrado y maestría en formación para el trabajo con la filosofía y la infancia. Para eso abordaremos la experiencia de formación llevada a cabo por el Núcleo de Estudios de Filosofías e Infancias entre 2017 y 2018. El texto propone reflexionar en qué medida la experiencia de formación no es solo un curso de formación en filosofía con niños, sino un tiempo escolar capaz de modificar nuestra relación con el conocimiento. De este modo, proponemos hacer una descripción del curso: cómo ocurre, la división de los grupos, la dinámica y la metodología. Así, trabajaremos el concepto de infancia, el cual fue la propuesta de nuestro grupo en 2017. Por último, abordaremos a los pedagogos belgas Masschelein y Simons para pensar tres aspectos del estudiante: atención, profanación y suspensión. Pensaremos en qué sentido esos aspectos estuvieron presentes en la experiencia de formación y cómo ellos influyeron en la transformación de nuestra relación con el conocimiento.

Palabras clave: filosofía con niños, infancia, atención, profanación, suspensión

\section{On childhood and philosophy: suspension, profanation, and attention in training experience}

\begin{abstract}
This article aims at analyzing our own experience as students from the undergraduate and postgraduate program in training in working with children and philosophy. For that purpose, we will address the training experience carried out by the Philosophy and Children Studies Group between 2017 and 2018. This text proposes a reflection on the extent to which training experience is not only a training course in philosophy with
\end{abstract}


children, but also a school time capable of modifying our relationship with knowledge. In this way, we propose to make a course description: its development, the organization of the groups, its dynamics, and its methodology. Thus, we will work on the concept of childhood, which was proposed for our group in 2017. Lastly, we will analyze Masschelein's and Simons' works in order to reflect on three school elements: attention, profanation, and suspension. We will study how these elements were manifested in training experience and how they influenced the transformation of our relationship with knowledge.

Keywords: philosophy with children, childhood, attention, profanation, suspension

\section{À propos de l'enfance et la philosophie : la suspension, la profanation et l'attention dans l'expérience de formation}

\section{Résumé}

Cet article a pour objectif d'analyser notre propre expérience en tant qu'étudiants en licence et en master en formation au travail avec les enfants et la philosophie. Dans ce but, nous aborderons l'expérience de formation vécue par le Groupe d'Études sur la Philosophie et les Enfants entre 2017 et 2018. Le texte propose de réfléchir à la mesure dans laquelle l'expérience de formation n'est pas seulement un cours de formation sur la philosophie avec les enfants, mais aussi un temps scolaire capable de modifier notre relation avec la connaissance. De cette façon, nous proposons de faire une description du cours : son développement, l'organisation des groupes, sa dynamique, et sa méthodologie. Ainsi, nous travaillerons sur le concept d'enfance, celui qui a étéla proposition de notre groupe en 2017. Enfin, nous analyserons les pédagogues belges Masschelein et Simons pour réfléchir à trois éléments scolaires : l'attention, la profanation, et la suspension. Nous étudierons dans quel sens ces éléments se sont manifestés dans l'expérience de formation et comment ils ont influencé la transformation de notre relation avec la connaissance.

Mots-clés : philosophie avec des enfants, enfance, attention, profanation, suspension 


\section{Introdução}

Nesse artigo iremos abordar a Experiência de Formação do Núcleo de Estudos de Filosofias e Infâncias [NEFI] que ocorre em Ilha Grande, no interior do estado do Rio de Janeiro, Brasil. A Experiência de Formação é um curso oferecido pelo NEFI. O núcleo colabora na formação de pesquisadores, estudantes e professores nas áreas de filosofia e infância.

O trabalho a ser apresentado trata-se mais de um relato de experiência, do que um artigo científico. A necessidade de pensarmos a própria experiência se deu na medida em que ela foi capaz de nos tirar do lugar. As experiências de formação que ocorreram em Ilha Grande nos últimos dois anos fizeram com que saíssemos outros, diferentes da maneira como lá entramos.

Partiremos da ideia de que pensamento e vida não estão separados. Assim, pensar uma formação em filosofia com crianças não apenas nos ensina algo sobre uma prática, um conhecimento, como também é capaz de transformar nossa relação com o conhecimento e a vida.

O curso realizado em Ilha Grande tem por metodologia a filosofia com crianças. Não se trata apenas de ensinar como fazer as experiências de uma maneira teórica, mas de executá-la e participar das experiências propostas pelos outros grupos. De uma maneira geral, o curso pode ser compreendido como uma formação para aqueles que trabalham, pesquisam ou se interessam pela filosofia com crianças. No entanto, o que caberá ser pensado nesse artigo é que, apesar do curso se constituir como uma experiência de cinco dias sediada em uma ilha na qual aprendemos a fazer experiências de filosofia com crianças, nos parece certo afirmar que o que se aprende de fato nessa experiência é uma relação com o pensamento, não um conteúdo ou uma matéria.

O que faz, segundo nossa percepção, com que o curso seja da forma como é? O que nos leva a tamanha imersão? Quais as características dessa formação que nos leva a uma experiência tal como iremos descrever aqui? Essas são perguntas que irão perpassar esse artigo, questionamentos que podem semear nosso reavivamento experiencial da ilha para tentar expressar uma fala ensaística sobre o pensamento. 
Para a escrita desse artigo vamos utilizar as anotações do diário de bordo feitas durante as duas edições do curso de formação. Com uma metodologia reflexiva, buscaremos, a partir do material que coletamos, remontar o caminho percorrido pelo grupo para a construção da experiência de filosofia, assim como relembrar as impressões vividas durante as experiências de outros grupos. De maneira geral, o material coletado é importante para pensarmos e escrevermos sobre as experiências vividas nas duas edições do curso de formação.

Os conceitos a serem trabalhados ao longo do artigo serão pensados a partir da análise dos registros pessoais dos autores, em uma tentativa de voltar a experiência vivida, não apenas como lembrança, mas como uma volta àquilo que ainda reverbera em nós, que ainda encontra-se presente e ecoa em nossa formação.

Como aporte teórico para nos auxiliar nesse trabalho abordaremos o conceito de infância. Para isso vamos utilizar Walter Kohan. Refletiremos também com os pedagogos belgas Masschelein e Simons a partir de seus livros Em defesa da escola: uma questão pública (2013) e A Pedagogia, a democracia e a escola (2014). Com Masschelein e Simons vamos pensar em que medida a experiência de formação em Ilha Grande se relaciona com os conceitos de atenção, suspensão e profanação, conceitos que estão presentes naquilo que os autores compreendem como escola enquanto forma.

Iniciaremos este artigo contando um pouco da história de onde é realizado o curso, o CEADS, campus da Universidade do Estado do Rio de Janeiro [UERJ], em Ilha Grande. Em seguida trabalharemos o conceito de infância e sua abordagem na experiência de filosofia proposta pelo grupo que fizemos parte em nossa primeira presença na ilha em 2017. Por último, retomaremos o relato de nossa experiência no curso de formação nos últimos dois anos em uma tentativa de relacionar com o conceito de skholé, mais especificamente a atenção, a profanação e a suspensão, em Masschelein e Simons.

\section{Sobre a organização da Experiência de Formação}

Nosanos de 2017e 2018, foram oferecidos cinco dias deimersãonessa experiência. A Formação contou com a presença de integrantes do 
NEFI, núcleo de estudos vinculado ao Programa de Pós-Graduação em Educação da UERJ. Também contou com a presença de pessoas de outros países e estados, somando, aproximadamente, um total de 40 pessoas, sendo elas professores, estudantes e pesquisadores vinculados ao NEFI.

O local escolhido para a realização do curso foi o CEADS, campus localizado na antiga área que compreendia o instituto penal Cândido Mendes, em Ilha Grande, no município de Angra dos Reis. A importância acadêmica deste campus constitui-se em seu objetivo que é gerar, difundir e aplicar o conhecimento para a melhoria da qualidade do meio ambiente e da vida dos seres humanos, concretizando-se através de processos integrados de ensino, pesquisa e extensão. No CEADS são realizadas pesquisas ambientais ligadas a fauna e flora do local, pesquisas sobre a vida marítima, cursos de formação - como é o nosso caso -, pesquisas na área de geologia, manutenção do Museu do Cárcere, onde era o antigo presídio, dentre outras.

A escolha do local nos parece ter uma significativa relevância, primeiro pela sua história, pois é uma área onde se localiza um antigo presídio desativado conhecido pelos seus presos políticos durante a ditadura militar brasileira, agora sob responsabilidade da UERJ. Segundo pela sua beleza, pois se trata de uma ilha composta por verdes ao seu redor e dois rios, um em cada extremidade da praia, antes de adentrar a mata. Terceiro pelo deslocamento físico necessário para chegarmos até o local, pois é necessário sairmos do campus principal da UERJ no Maracanã, bairro da zona norte do Rio de Janeiro às 6:0oh. Chegamos em uma pequena cidade chamada Conceição de Jacareí por volta das 8:ooh para pegarmos uma barca até a Ilha Grande e lá um ônibus da universidade até o outro lado da ilha, onde fica o CEADS. O percurso total gira em torno de $5: 30 h$.

\section{Sobre a Experiência de Formação}

O que era a formação? Como ela acontecia? O curso iniciou com uma dinâmica para dividir os grupos de trabalho. A proposta se tratava de um jogo, uma grande cartolina fazia o papel de quadro no qual encontrávamos três opções: aprender com, aprender de e ensinar. Cada participante a sua vez dizia um nome daquele que 
ali estava presente para preencher o quadro. Ao final os cinco mais pontuados, segundo os critérios de pontuação do jogo, seriam as responsáveis pela montagem dos grupos.

Separados os grupos, nos foi orientado montar uma experiência de pensamento. Tínhamos um acervo de materiais para desenvolvê-los. Eram livros infantis, cartolinas, folhas coloridas, canetinhas, tinta guache, pincel, além do próprio material que a ilha nos oferecia, ou seja, as árvores, a paisagem, um vilarejo quase deserto, o mar, as folhas secas, etc... A experiência de pensamento seria ofertada aos demais participantes da formação. Os próximos dias seriam de apresentações durante o dia e pela noite. Quem ainda não tinha apresentado reunia-se com seu grupo para pensar e se preparar.

Cada dia que passava eram experienciadas temáticas e didáticas diversas, pensando em conjunto o que nos era proposto por cada grupo, como, por exemplo, a morte, a infância, a escola, a filosofia, o passado, o presente, os sentidos e os sentimentos. Cada grupo, nos levava à uma infinita reflexão sobre muitas coisas, uma vez que era a partir dessas experiências vividas que tínhamos, também, a chance de pensarmos em nós mesmos, em nossa relação com a prática da educação, em nossa vivência de mundo, em nossa relação com a busca do conhecimento e com a vida.

Com o objetivo de fazer dialogar filosofia e infância sob a forma de um relato, abordaremos a experiência vivida por nós - as autoras e autor do texto - enquanto grupo. Vale lembrar que toda experiência de rememorar e explicar um acontecimento oferece no próprio exercício do (re)lembrar uma possibilidade de (re)viver (Ferraro, 2018). Assim, (re)viver a memória de um acontecimento é (re)criar um pensamento. Por isso, (re)criaremos nosso relato para conceder uma potência de pensamento acerca da nossa vivência ilhística.

\section{Experienciar o pensamento, pensar a experiência}

Como já foi dito, o curso de formação utiliza como método a própria filosofia com crianças. Kohan e Olarieta no primeiro capítulo do livro intitulado $A$ escola pública aposta no pensamento (2012, p. 20) descrevem seis momentos que compõem uma experiência de filosofia, são eles: a) disposição inicial - com o objetivo de facilitar 
ou enriquecer a relação das crianças com a discussão filosófica; b) vivência (leitura) de um texto - compreende-se texto em suas mais diversas concepções, trata-se mais objetivamente de levar algo que provoque o pensamento, pode ser um poema, um texto filosófico, uma imagem, um som, enfim, tudo aquilo que pareça ser potente para o pensar; c) problematização de um texto, levantamento de temas/questões - nesse momento são levantadas questões sobre o texto apresentado, ele é problematizado; d) escolha de temas/questões - com a problematização do texto apresentado é preciso focar em um dos temas ou questão que surgiu durante a problematização; e) diálogo - o momento do diálogo é parte fundamental da experiência de filosofia, regado de por quês e para quês, esse é o momento que os participantes trocam entre si; f) para continuar pensando - o último momento trata-se de uma avaliação da experiência, o objetivo é recuperar a experiência e pensar sobre ela.

No entanto, para além da maneira como é organizada a prática da experiência de formação, Berle (2018) em seu livro Infância como caminho de pesquisa: O núcleo de estudos de Filosofias e Infâncias (NEFI/PROPED/UERJ) e a educação filosófica de professoras e professores, nos faz pensar sobre a metodologia do NEFI. Berle (2018) nos diz:

Experienciar o pensar, "pensar a experiência" surge como movimento inicial de reunião para pensar coletivamente sobre algo. O modo como esse movimento se desenrola é o foco do que pode ser percebido como segundo movimento "pensar a experiência". Essa é a base de todos os encontros promovidos pelo NEFI. (p. 206)

Para a escrita do trecho acima, Berle recorre a entrevista de Kohan presente no livro organizado por ele e Olarieta $-A$ escola pública aposta no pensamento (2012). No capítulo intitulado Um encontro na conversa; uma conversa no encontro, Kohan, ao ser questionado por Ana Corina Salas sobre as reuniões feitas com professores e alunos para se pensar a filosofia, afirma:

Pois nós tratamos de trabalhar sempre da mesma maneira, com meninos e meninas, com os docentes das escolas, entre os estudantes e professores da universidade: nossos espaços de formação são sempre marcados pela lógica da experiência: nós nos reunimos para experienciar o pensamento e pensar a 
experiência. Este é o duplo movimento que afirmamos sempre, ou ao menos tratamos de fazê-lo e, para isso, nos reunimos, para insistir e aprofundar o valor e o sentido da experiência de pensar juntos o que nos interessa. De modo que nosso modo de trabalho segue essa lógica em que pensamos, experimentamos o pensar e ao mesmo tempo nos distanciamos dessa experiência no próprio pensamento para voltar sobre ela e desdobrá-la um pouco mais, dar-lhe outra volta, revolver um pouco seus sentidos. Creio que este é o jogo da filosofia: com crianças, adultos ou com quem seja. (Kohan \& Olarieta, 2012, p. 164)

Pensando com Berle, a partir da afirmação de Kohan, diríamos que a experiência de formação segue a mesma metodologia proposta para os outros encontros do NEFI. Trata-se de experienciar o pensamento e pensar a experiência.

Isso pode ser notado na experiência de formação na medida que inicialmente os grupos propõem uma experiência de pensamento. A partir da experiência de filosofia com crianças é proposto pelos grupos um tema sobre o qual os outros participantes do curso irão dedicar seu tempo e atenção, para que assim, após experienciarmos o pensamento, possamos pensar a experiência.

Desse modo, essa escrita é de certa forma a continuação da experiência, pois trata de pensá-la, de voltar a ela para continuar pensando sobre a experiência vivida, como uma continuação daquilo que foi realizado em Ilha Grande. Trata-se de pensar a partir daquilo que ficou em nós após as duas vivências.

\section{Pensando a infância}

Nosso grupo apresentou a experiência no último dia, pela manhã, demoramos muito até achar uma consonância entre nós. Já desacreditados e desanimados, sentamos na areia da praia. Era de manhã e a maré tinha acabado de descer, deixando a areia bem durinha e agarrando na nossa roupa, quando começamos a apalpar a areia, fazer montinhos e de repente já estávamos montando um castelo, com um forte na frente e um rio na lateral que enchia toda vez que a onda chegava bem mansinha. Pronto, era isso! Naquele momento pensamos juntos que não adiantaria ter mil teorias sobre a infância se não nos permitíssemos entendê-la, enxergá-la, vivê-la a partir de sua ótica. 
Para pensar a ótica infante, utilizamos a ideia de Lyotard contida no texto Visões de Filosofia: Infância (Kohan, 2015) que acompanha o ser humano durante toda a sua vida. Nos deixamos invadir os pensamentos pelo eu infante que estávamos suprimindo desde o começo. Queríamos falar sobre a infância, mas não estávamos pensando com ela. Quando passamos a pensar com ela e percebemos sua linguagem, conseguimos, enfim, montar nossa experiência.

Um segundo autor utilizado para pensar o conceito de infância foi o filósofo grego pré-socrático Heráclito. Pensar com Heráclito (Kohan \& Vigna, 2013) era um dos livros disponíveis para a leitura durante a experiência de formação. Nele encontramos o fragmento 52: "O tempo é uma criança que brinca; o reino de uma criança". É importante notar que a tradução de tempo presente em Heráclito é a tradução do termo aíon - o tempo compreendido em sua dimensão de experiência. Ora, não seria essa mesma forma de compreender o tempo em Kohan quando este aborda a infância?

Em ¿Para qué hacer filosofía con ninãs y niños en América Latina? (2013b) Kohan pensa a vida em sua relação com o tempo. Com esse objetivo o autor diferencia os tempos khrónos e aíon. O primeiro seria o tempo como número de movimento. Esse seria o tempo comumente concebido. A partir dele a infância é compreendida como uma etapa da vida.

No entanto, é possível pensar o tempo de outras maneiras, não apenas quantitativamente. $\mathrm{O}$ tempo pode ser pensado em sua dimensão experiência, ou seja, não mais a partir de khrónos, mas a partir do tempo aíon, o mesmo tempo relacionado com a infância presente no fragmento 52 de Heráclito. Pensar a infância em sua dimensão experiência significa afirmar que a infância não é - apenas - uma etapa da vida, mas uma forma de experienciá-la, de vivê-la.

É importante ressaltar que as duas maneiras de compreender a infância em sua relação com o tempo não se excluem. Existem aqueles que estão em sua infância khrónos experienciando a infância aíon. Da mesma maneira, encontramos infâncias aíon em adultos ou mesmo crianças sem infância aíon. Mas se a infância krhonós é compreendida como uma etapa da vida, como podemos compreender a infância aíon? Segundo Kohan ela é compreendida pela sua forma de experienciar o mundo, de uma experiência infantil 
do mundo, uma experiência de início, como se fosse a primeira vez (Kohan, 2013b).

A partir dessa concepção de infância partimos para a elaboração da experiência, o objetivo seria então pensar o conceito de infância. Se era certo que ali já não havia infância em sua relação com o tempo cronológico nos perguntávamos sobre a possibilidade de vivenciarmos a infância em sua relação com o tempo aíonico.

Assim, comoobjetivodetrabalharoconceitodeinfância,fizemos um caça ao tesouro no qual foram dadas pistas com enigmas que quando decifradas levaram o grupo a uma determinada localização onde se encontrariam de 5 a 6 pessoas, como por exemplo: "Dirijase até o panóptico de Foucault e espere até o quinto membro do grupo". A pista faz referência à teoria que Foucault (1987, p. 166) disserta sobre o conceito do panoptismo, o que constitui-se, de maneira geral, tomar integralmente o poder disciplinador da vida de um indivíduo, onde o mesmo é vigiado durante todo o tempo, sem que consiga ver o seu observador e muito menos o momento em que se é vigiado. A analogia foi feita com o objetivo de reunir o grupo em uma guarita que deveria medir em torno de dois metros de altura, localizada atrás do CEADS e em frente à antiga prisão. Assim como essa foram distribuídas outras pistas para a formação dos grupos, sempre utilizando os elementos oferecidos pela ilha, ou seja, o antigo presídio, os antigos carros da universidade, o orelhão enferrujado.

Após a composição do grupo, deveriam juntos seguir a segunda orientação sobre o tesouro, que só poderia ser aberto na praia. $\mathrm{O}$ tesouro era composto por livros infantis e uma proposta final que consistia na leitura do livro por todos os membros do grupo para a partir disso montarem uma dinâmica utilizando os elementos de acordo com aquilo que a leitura potencializava o pensar, relacionando isso à infância.

Tivemos um grupo que enterrou uma participante na areia e sob seu corpo fez uma cauda de sereia; outro que montou uma espécie de território ou caverna com galhos secos que estavam na areia; participantes que cantaram, já que ao vivenciarem suas infâncias cantarolavam sobre as histórias de seus tesouros.

O que poderia, então, ser apreendido a partir desse exercício filosófico? No momento final de nossa apresentação quando 
pensávamos a experiência, percebemos que não foi apenas uma maneira de compreender a infância que foi vivenciada pelos participantes. Se por um lado é certo dizer que alguns deles afirmaram ter de fato vivido algo como se fosse a primeira vez, quando foi pedido para que criassem algo infantilmente, outros revisitaram sua infância cronológica, fazendo um movimento de retorno ao tempo passado recordando as impressões de sua própria infância khrónos, o que de certa forma nos fez pensar sobre os conceitos de infância e filosofia. Um infante que filosofa, um filósofo que brinca.

Kohan (2015) ao escrever sobre a relação entre filosofia e infância traz como fundamento a figura de Sócrates, um filósofo que seria um infante do pensamento, alguém que deu à filosofia uma infância como modo de vida, e não apenas como uma fase cronológica. Essa postura dialoga também com o autor Lyotard, visto que, este constitui em seu conceito de infância uma forma do inumano que acompanha o ser humano por toda a vida.

$\mathrm{O}$ autor defende a ideia, que Lyotard afirma, que infância e filosofia ajudam uma a outra, uma vez que a filosofia nada mais é do que a infância do pensamento (Kohan, 2015). A infinidade de forças de recomeços que tem o pensamento, que por sua vez é gerido pela pergunta, nos exemplifica que, ao pensar estamos sempre a recomeçar. $\mathrm{O}$ que exige colocar a si mesmo em questão, pensar profundamente. De maneira que tal exercício demanda voltar até a mais íntima infância do pensamento, pensando como se assim fosse a primeira vez, como se nunca o tivesse feito antes, nas palavras de Kohan (2015, p. 2): "assim, a infância é quase uma condição da filosofia".

Refletimos, a partir dessas palavras e ideias, sobre o momento em que o grupo que participávamos não conseguia definir um tema para a apresentação. Pensamos durante dias, perpassamos uma dezena de livros, pedimos ajuda ao professor Kohan, coordenador do curso, ficamos horas sem conseguir ter um pensamento sobre alguma coisa e, quando conseguimos, não sabíamos uma maneira de colocar em prática.

A ótica infante de Sócrates, segundo Kohan (2015), fundamentado em Heller (1978) e Derrida (1997), afirma ser uma maneira para filosofar em qualquer momento, seja pela forma em 
que compôs o lugar da filosofia entre a morte e a vida ou pelas inúmeras maneiras de existência que ele tinha: "estrangeiro, intratável, perguntador, incômodo, sem lugar, o mais sem lugar (atopóstatos) de todos, talvez o mais infante em Atenas, a única cidade onde podia viver" (p. 218) e sobre o momento de seu julgamento.

Sócrates, ao utilizar sua linguagem de infância, com a qual foi criado, educado, a utilizava para conversar com as pessoas nas ruas da cidade. Faz uso dessa linguagem como se diante do perigo da morte, ele recorresse à infância. De maneira a improvisar, como se não falasse a língua dos adultos e fosse, assim, um estrangeiro acolhido em sua infância. A ótica infante, que ora acolhia Sócrates no perigo da morte, agora nos permitia ali, naquele momento, experienciar a potencialidade da infância e filosofar juntamente com ela.

Podemos, também, observar essa movimentação, ainda dialogando com esse contexto da ótica infante, que enxerga o mundo como se fosse a primeira vez, a partir da nossa segunda Experiência de Formação na Ilha grande, dessa vez já em 2018. Viveríamos, novamente, em um outro espaço e tempo, a mesma experiência. Porém, esse nos demandou, mais uma vez, voltar até a nossa mais íntima infância do pensamento. Visto que, apesar de aparentemente estar acontecendo tudo igual, ali, naquele momento da experiência tudo aconteceu como se fosse a primeira vez, como se nunca o tivesse feito antes. A dinâmica era a mesma, mas a sensação era diferente. Já sabíamos o que ia acontecer, mas não sabíamos como íamos viver aquele momento. Embora tudo fosse igual, tudo acontecia diferente. As pessoas já não eram mais as mesmas do ano anterior, nem mesmo as ideias, as experiências, a cor do CEADS, as folhas e a nossa percepção. Embora vivêssemos novamente um momento, ele não era mais o mesmo de antes. Vivenciávamos cada momento de sua existência, através de nossa ótica infante, onde enxergávamos tudo como se fosse, novamente, a primeira vez.

\section{A experiência de formação como tempo livre}

Seguimos assim para a segunda parte deste artigo, pensar em que medida o exercício que vivemos na experiência de formação pode se relacionar com os conceitos de atenção, profanação e suspensão 
em Masschelein e Simons. Em Em defesa da escola: Uma questão pública (2013), os autores nos apresentam oito aspectos daquilo que seria o escolar, ou aquilo que faz de escola uma escola. São eles, a suspensão, a profanação, a atenção e o mundo, a tecnologia, a igualdade, o amor, a preparação e a responsabilidade pedagógica.

O primeiro ponto importante para que possamos compreender a relação entre a formação em Ilha Grande e os três conceitos a serem trabalhados é entender que segundo Masschelein e Simons $(2013$; 2014) para que haja uma escola, tal como eles a definem, isso é, enquanto tempo livre, a mesma não necessita de uma instituição. Isto é, não é a instituição escolar, com todas as suas regras, provas, horários, que garante que a escola de fato aconteça. A escola enquanto tempo livre pode estar inserida em uma instituição, porém não precisa dela para existir, pois o que garante sua existência são os oito princípios citados acima.

Para esse artigo abordaremos três desses princípios, os três que nos parecem mais interessantes para pensarmos nossa experiência em Ilha Grande. A suspensão, a profanação e a atenção. Não diríamos que os outros cinco princípios do escolar não estariam presentes na experiência que fizemos na ilha. No entanto, nos parece mais interessante pensar a partir desses, uma vez que, eles foram os quais nos tocaram durante o período da experiência de formação.

\section{A suspensão}

A suspensão, segundo Masschelein e Simons (2013), pode ser definida como suspender as regras políticas, sociais e econômicas. Isso acontece da seguinte maneira: a escola seria capaz de deixar para trás, ou melhor, deixar fora dos seus muros tudo aquilo que define um aluno a partir dos critérios da sociedade. Um exemplo que nos parece esclarecer o que os pedagogos chamam de suspensão é a escola que é construída na atual Bolívia, na cidade Chuquisaca em 1825 pelo filósofo e educador venezuelano Simón Rodríguez. (Kohan \& Dúran, 2018)

A escola de Chuquisaca foi capaz de suspender os critérios impostos pela sociedade, isso é, as regras da escola eram outras que a sociedade queria impor. 
Naquele momento, logo após a independência da Bolívia, a sociedade era dividida por castas, castas essas que dentre outras coisas separavam as crianças em escolas segundo sua origem familiar. O que Simón Rodríguez foi capaz de fazer foi deixar do lado de fora aquilo que fazia com que a sociedade definisse cada criança segundo sua origem familiar, econômica e social, ou melhor, segundo sua origem étnica. Com outras palavras, a escola de Chuquisaca foi capaz de suspender as regras da sociedade. Essa ideia pode ser confirmada no livro escrito por Kohan sobre o educador venezuelano, $O$ mestre inventor: relatos de um viajante educador (2013a):

$\mathrm{Na}$ escola de Chuquisaca não se discriminam as crianças por causa de sua cor de pele, seu sexo, a classe a que pertencem, a família em que nascem, suas crenças religiosas ou a língua que falam, como de costume nas escolas de primeiras letras na Colônia. Ao contrário, ao entrar na escola popular, suspendemse as desigualdades geradas pelas diferentes tradições, famílias, classes sociais. (p. 93)

Masschelein e Simons (2013) afirmam que entrar na escola é como descascar as camadas de uma cebola. O estudante que ali adentra o faz com uma série de expectativas da sociedade que diz quem ele é e quem ele deve vir a ser segundo sua origem. Os autores nos alertam que pensamentos como: "filhos de cozinheiro não gostam de matemática”, devem estar fora da escola, pois são pensamentos como esses que tendem a definir os alunos segundo suas famílias, segundo seu lugar de origem e sua classe econômica.

No entanto, nos parece importante ressaltar que para os pedagogos belgas o que está em jogo é apenas a suspensão das expectativas em cima dos estudantes segundo suas origens. $\mathrm{Ou}$ seja, não se trata de apagar o passado do estudante, mas sim de admitir que a história de alguém não se encerra em seu passado e que ele pode se reinventar, fazer dele o que ele quer vir a ser ao invés de aceitar o que a sociedade quer fazer dele.

A suspensão parece se fazer presente no curso de formação quando não é levado em conta se aquele que faz o curso é estudante de graduação, pesquisador, professor universitário, estrangeiro ou brasileiro. A origem familiar, acadêmica, social e econômica não é levada em conta, ou melhor, é suspensa enquanto nos encontramos na ilha. 
Isso pode ser observado já na divisão de grupos, quando um jogo define quem irá trabalhar com quem, independentemente de sua origem para além da ilha. A suspensão também pode ser observada durante o desenvolver das atividades, no momento em que todos são capazes de opinar na montagem da experiência de filosofia, ou mesmo na execução da própria experiência de filosofia, pois que todos são ouvidos, independentemente de serem professores, estudantes ou pesquisadores, quando estão fora da formação.

\section{A profanação}

O segundo conceito que vamos trabalhar é a profanação. O outro lado da moeda da suspensão, a profanação significa retirar o caráter de sagrado das coisas (Masschelein \& Simons, 2013). Profanar é tornar algo aberto e disponível para novos usos e significados no estudo e na prática (Masschelein \& Simons, 2013). Assim, a profanação consiste em tirar algo de seu uso habitual, tornando-o público para que todos possam dar a ele novo significado.

A imagem trazida pelos autores, para a compreensão desse conceito, é a ideia de disponibilizar o conhecimento "em cima da mesa”. O professor é o responsável por trazer o conhecimento para sala de aula e disponibilizá-lo em cima da mesa ou no quadro, para utilizarmos uma imagem mais escolar. Na medida em que esse conhecimento entra na sala de aula ele já não pertence a um ou a outro, mas se torna disponível para que todos e qualquer um possa profaná-lo. Ou seja, ele se torna público e pode ganhar novos significados.

Um tempo e lugar profano, mas também, as coisas profanas, referem-se a algo que é desligado do uso habitual, não mais sagrado ou ocupado por um significado específico, e portanto, algo no mundo que é, ao mesmo tempo, acessível a todos e sujeito à reapropriação de significado. É algo, nesse sentido geral (não religioso), que foi corrompido ou expropriado; em outras palavras, algo que se tornou público. (Masschelein \& Simons, 2013, p. 39)

Durante nossa experiência na ilha, a profanação parece ter se dado quando trabalhamos na experiência de filosofia que propomos para o grupo. Como já dissemos, nossa proposta consistia em trabalhar o conceito de infância, para isso partimos do caçatesouros e da construção de algo a partir do tesouro encontrado. 
Diríamos que a profanação pareceu estar presente na medida em que os grupos faziam dos materiais disponíveis outras coisas que não o habitual. Isso é, sendo o espaço escolhido pelo grupo para a realização da experiência a beira da praia, ali encontrávamos materiais comuns nesses espaços, como areia, galho seco, pedras, pedaços de madeira, conchas, folhas. No entanto, esses materiais que estavam ali disponíveis para todos, no momento da atividade, ganhavam novos usos. A areia da praia já não era areia para se deitar e pegar sol, mas se convertia em um palco onde foi feita uma apresentação musical. Os galhos secos com as folhas que caiam das árvores tantas vezes descartados e deixados de lado pelos banhistas, já não eram galhos e folhas, mas uma bela cabana. Ou seja, as coisas já não eram aquilo que elas habitualmente eram, pois se encontravam disponíveis para que todos pudessem fazer delas algo diferente do habitual.

\section{A atenção}

A atenção, o terceiro conceito que queremos trazer para pensar, nos parece importante nesse momento. Segundo Masschelein e Simons (2013) "o tempo livre como escolar não é um tempo para diversão ou relaxamento, mas é um tempo para prestar atenção ao mundo, para respeitar, para estar presente, para encontrar, para aprender e descobrir" (p. 98) ${ }^{1}$.

É exatamente isso o que nos parece acontecer na experiência de formação que ocorre em Ilha Grande, ao menos nas duas últimas edições nas quais estávamos presentes. Somos colocados em total estado de atenção para que as coisas nos façam pensar. Se por um lado não podemos garantir que o pensamento aconteça, por outro podemos afirmar que as condições são dadas para que isso possa ocorrer. No entanto, quais seriam as condições para que a atenção possa se fazer presente?

Diríamos que a suspensão e a profanação cumpririam essa condição, pois que por um lado a profanação libera as coisas de seu uso habitual. Coloca-as disponíveis para que elas possam se tornar públicas fazendo com que possamos atribuir à elas novos significados. Por outro lado, a suspensão nos livra das amarras que

1 Grifo nosso. 
a sociedade nos impõe; sejam as amarras do passado, nossa origem, sejam as amarras do futuro, quem a sociedade quer que venhamos a ser. Assim, nos encontramos no presente, ou como Masschelein e Simons nos dizem, no indicativo presente, no aqui e agora (2013; 2014).

Desse modo a profanação e a suspensão criam o espaço/tempo necessário para que possamos nos encontrar atentos aquilo que o professor trás do mundo e coloca disponível na mesa. No caso de Ilha Grande, todos éramos professores e alunos a sua vez, de maneira que por vezes éramos nós que disponibilizamos algo a ser pensado e outras vezes dedicávamos nossa atenção naquilo que estava disponível para ser pensado.

\section{Conclusão}

Assim, compreendemos que a Experiência de Formação realizada pelo NEFI, ainda que utilize a filosofia com crianças em sua metodologia é mais do que um curso de filosofia com crianças. Ela se constitui como um espaço/tempo de profanação, suspensão e atenção, capaz de fazer com que as coisas ganhem novos significados, capaz de suspender nossa relação habitual com o mundo.

A Experiência de Formação é uma imersão no pensamento, capaz de criar as condições de possibilidade para que possamos ter tempo e disponibilidade para nos debruçar sobre as coisas do mundo e nos fazer pensar nelas, com elas, sobre elas. Nesse sentido, a experiência de formação se constitui como um fazer escola, compreendendo escola como tempo livre (Masschelein \& Simons, 2013).

No entanto, um fazer escola enquanto forma: apesar de não descartar a instituição UERJ que se encontra por trás dessa formação, pois ela proporciona o espaço de uma ilha, a estrutura de um alojamento, a alimentação, o transporte e a liberação do tempo, é a forma escola a responsável por fazer possível a nossa transformação.

Assim, se por um lado a forma é a condição de possibilidade para que o pensamento aconteça e com ele a transformação da nossa relação com o conhecimento, com as coisas do mundo e com a própria vida, a instituição parece nos auxiliar com a tecnologia necessária para que a forma se faça possível. 
Concluindo, apesar de afirmarmos a sensação de estar ali sempre como se fosse a primeira vez, nos parece certo afirmar que a repetição também se fez presente. A repetição estava presente na medida que nas duas vezes que estivemos aí notamos a profanação, a suspensão e a atenção. Ela estava presente na dinâmica das construções de grupo, na metodologia proposta, nas experiências de filosofia com crianças - embora realizadas com adultos em seu tempo cronológico. Por outro lado, a repetição parecia gerar reações diferentes, de modo que, embora a transformação tenha se dado nos dois momentos, talvez ela não tenha sido a mesma.

\section{Referências}

Berle, S. (2018). Infância como caminho de pesquisa: O núcleo de estudos de Filosofias e Infâncias (NEFI/PROPED/UERJ) e a educação filosófica de professoras e professores. Rio de Janeiro: Nefi edições.

Ferraro, G. (2018). Escola dos sentimentos. Rio de Janeiro: Nefi edições.

Foucault, M. (1987). Vigiar e punir: nascimento da prisão. Petrópolis, Brasil: Vozes.

Kohan, W. (2013a). O mestre inventor: Relatos de um viajante educador. Belo Horizonte: Autêntica.

Kohan, W. (2013b). ¿Para qué hacer filosofía con niñas y niños en América Latina? Iberoamericana, 35(2), 1-9.

Kohan, W. (2015). Visões de filosofia: infância. Alea: Estudos Neolatinos, 17(2), 216-226. https://dx.doi.org/10.1590/1517-106X/172-216

Kohan, W., \& Dúran, M. (2018). Manifesto por uma educação filosófica popular. Rio de Janeiro, Brasil: Nefi edições.

Kohan, W., \& Olarieta, F. (2012). A escola pública aposta no pensamento. Rio de Janeiro, Brasil: FAPERJ.

Kohan, W., \& Vigna, E. (2013). Pensar com Heráclito. Rio de Janeiro: Lamparina.

Masschelein, J., \& Simons, M. (2013). Em defesa da escola: Uma questão pública. Belo Horizonte, Brasil: Autêntica.

Masschelein, J., \& Simons, M. (2014). A pedagogia, a democracia, a escola. Belo Horizonte, Brasil: Autêntica. 